Epidemiology

\title{
The human genome requires physical activity: What are we learning from COVID-19?
}

\author{
Odilon Abrahin $^{1}$ (D), Rejane P. Rodrigues ${ }^{1,2}$ (D), Evitom C. Sousa ${ }^{2}$ (D), João Guerreiro ${ }^{1}$ (D) \\ ${ }^{1}$ Programa de Pós-graduação em Genética e Biologia Molecular, Universidade Federal do Pará, \\ Belém, PA, Brazi; ${ }^{2}$ Laboratório de Exercício Resistido e Saúde, Universidade do Estado do Pará, \\ Belém, PA, Brazil.
}

Associate Editor: Mariana Ferreira de Souza (D), Universidade Federal do Vale do São Francisco, Petrolina, PE, Brazil. E-mail: mariana.ferreirasouza@univasf.edu.br.

\begin{abstract}
Aim: The primary cause for the development and worsening of chronic diseases is physical inactivity. This article aims to present a proposal for the negative impacts of physical inactivity during social distancing caused by the COVID-19 pandemic. Results: Global levels of physical activity are decreasing, and this behavior can be the start to increase the prevalence and incidence of chronic diseases such as diabetes, high blood pressure, obesity, and mental illness after the COVID-19 pandemic. Conclusion: Staying physically active is a fundamental behavior during the COVID-19 pandemic and social distancing.
\end{abstract}

Keywords: COVID-19, social distancing, exercise, health.

\section{Introduction}

The primary cause for the development and worsening of chronic diseases (obesity, diabetes mellitus, systemic arterial hypertension, metabolic syndrome, cancer, coronary artery disease, sarcopenia, osteoporosis, among others) is physical inactivity ${ }^{1,2}$. We need to understand that the human genome was programmed to perform physical activity, and muscle contraction is a physiological need that stimulates and aids in the homeostasis of several systems ${ }^{2}$, such as the cardiovascular, cardiorespiratory, neuroendocrine, and immune systems.

Clinical and experimental studies support the theory that the mismatch between the human genome "shaped" centuries ago (10000 BC) and the poor physical activity environment experienced by modern man (2011 AD) is the link between chronic diseases pandemic that affects contemporary society ${ }^{1}$. Booth and Lees ${ }^{2}$ exemplify the need for physical activity since $10000 \mathrm{BC}$, in which fighting, hunting, and flight were survival necessities. In other words, only the strong and fast could survive and could, thus, reproduce, consequently passing on genes to future generations, and those who were not successful in hunting, fighting, and fleeing did not survive. Therefore, a natural selection was already in place (Darwin's Theory), which depended on physical fitness and the wise use of the locomotor system ${ }^{2}$.

Historically, physical inactivity is a predominant factor in contemporary society when compared to other periods. For example, in the Paleolithic period ${ }^{3}(\sim 20000$
BC), men performed between $\sim 13200-21120$ steps per day, and women $\sim 10560$. Currently, adult men in the United States perform ${ }^{4} \sim 5340$ steps per day, and women 4912. A multicenter study ${ }^{5}$ carried out in Europe (Denmark, Spain, Germany, and the United Kingdom) estimated that elderly people take about $\sim 5000 \pm 2596.9$ steps per day. A Brazilian study showed that men performing $\geq 10000$ steps per day have better cardiometabolic conditions than those walking $<10000$ steps per day ${ }^{6}$. These data demonstrate that we are presenting hypokinetic behavior, in which we no longer stimulate the main gland in the human body, the skeletal muscle ${ }^{7}$.

In this sense, skeletal muscle tissue is considered an endocrine/paracrine organ, and muscle actions are performed at appropriate intensities and volumes secrete substances displaying anti-inflammatory characteristics, called myocins ${ }^{7}$. Long periods of physical inactivity can lead to negative physiological responses, such as resistance to insulin action, subclinical inflammations, protein degradation, pain, and increased morbidity and mortality risks $^{8}$. The classic "Dallas bed rest" study ${ }^{9}$, published in 1968 in the journal Circulation, simulated the clinical treatment of acute myocardial infarction in healthy young patients, which consisted of being completely bedridden for three weeks. The results indicated decreased $\mathrm{VO}_{2 \max }$, cardiac output, and systolic effort volume after three weeks.

Another study ${ }^{8}$ simulated a rigorous bed rest (bedridden) of one week in healthy young adults (age $23 \pm 1$ years; BMI $23.0 \pm 0.9 \mathrm{~kg} \mathrm{~m}^{2}$ ), revealing significant 
muscle mass reduction of $1.4 \pm 0.2 \mathrm{~kg}$, and a $3.2 \pm$ $0.9 \%$ decline in the quadriceps femoris, in addition to a significant decline in peak $\mathrm{VO}_{2}$ and muscle strength. Strict bed rest also induced a $29 \% \pm 5$ loss in insulin sensitivity. In fact, hypokinesia does not only cause deleterious locomotor system effects, but also systemic deleterious effects.

Studies involving molecular biology also emphasize and prove the need for physical activity. A study evaluated epigenetic changes (muscle biopsy) after three months of aerobic training (45 min; 4 sessions per week) following the training in only one randomized leg (trained leg), while the second leg (untrained leg) was used as an intraindividual control leg in young adults ${ }^{10}$. The results demonstrated that increased DNA methylation was associated with glucose metabolism and muscle fiber remodeling, while, on the other hand, decreased methylation was associated with the signaling of elements involved in inflammatory processes. The authors also concluded that aerobic training induced significant methylation changes at almost 5000 genome sites and the significant expression of approximately 4000 genes (PPARG, RUNX1, MIPEP, COL4A1, and others) ${ }^{10}$.

On January 30, 2020, the World Health Organization stated that the outbreak of coronavirus disease 2019
(COVID-19) caused by the new coronavirus (SARS-CoV2) constituted a "public health emergency of international concern". This virus has a high transmissibility power between humans and an infected person can transmit the virus, on average, to four people ${ }^{11}$. On the other hand, social distancing is decreasing global physical activity levels ${ }^{12}$, increasing the prevalence and incidence of several chronic diseases (Figure 1).

A systematic review demonstrated that genetic risk factors can affect the treatment and prevention of COVID19 , and physical inactivity is a strong modifiable risk factor for severe COVID-19 ${ }^{13,14}$. Tison et al ${ }^{12}$ examined worldwide changes in step count before and after the announcement of COVID-19 as a global pandemic. The results showed that worldwide, within 10 days of the pandemic declaration, there was a $5.5 \%$ decrease in mean steps (287 steps), and within 30 days, there was a $27.3 \%$ decrease in mean steps (1432 steps).

A Brazilian study described the lifestyle changes of 45,161 individuals during the period of social distancing in the COVID-19 pandemic ${ }^{15}$. The results showed that before COVID-19, $30.1 \%$ of adults were doing enough physical activity, while during the pandemic, this percentage decreased to $12.0 \%$. However, during social distancing, increased time in front of the screens, ingestion of ultra-processed foods, in the number of cigarettes smoked,
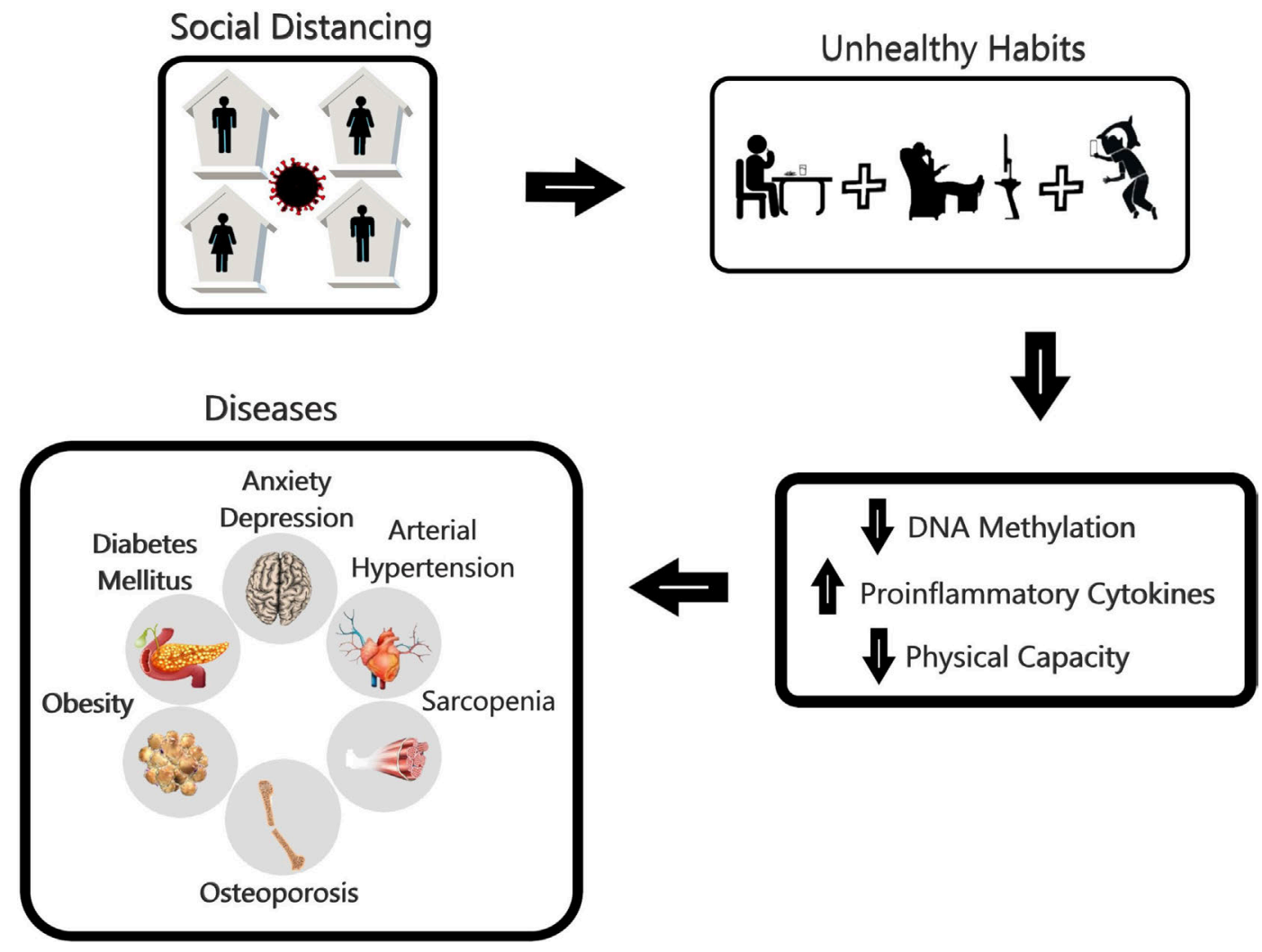

Figure 1 - Relationship between social distancing, physical inactivity, and chronic diseases. 
and in the consumption of alcoholic beverages were reported.

\section{Conclusion}

In this case, we present our two hypotheses; 1) Many people will become ill during social distancing, and, as this is a multifactorial issue, with the development and aggravation of chronic diseases due, in part, to physical inactivity. 2) We will observe chronic and mental illness pandemics, such as obesity, type 2 diabetes, sarcopenia, dyslipidemia, arterial hypertension, cancer, metabolic syndrome, depression, and anxiety, among others, after the Covid-19 epidemic. Thus, we strongly believe that staying physically active is a fundamental behavior during the Covid-19 pandemic and social distancing. What physical activity should be prescribed during social distancing? Several options can be practiced such as exergames, resistance training with body weight, high-intensity interval training, dance, yoga, endurance exercise (walking if viable), or adapt their activities to be performed at home.

\section{References}

1. Booth FW, Roberts CK, Laye MJ. Lack of exercise is a major cause of chronic diseases. Compr Physiol. 2012;2 (2):1143-211.

2. Booth FW, Lees SJ. Fundamental questions about genes, inactivity, and chronic diseases. Physiol Genomics. 2007;28 (2):146-57.

3. O'Keefe JH, Vogel R, Lavie CJ, Cordain L. Achieving hunter-gatherer fitness in the 21(st) century: back to the future. Am J Med. 2010;123(12):1082-6.

4. Bassett DR, Wyatt HR, Thompson H, John C, Peters, James $\mathrm{OH}$. Pedometer-measured physical activity and health behaviors in U.S. adults. Med Sci Sports Exerc. 2010;42(10): 1819-25.

5. Giné-Garriga M, Sansano-Nadal O, Tully MA, Caserotti $P$, Coll-Planas L, Rothenbacher D, et al. Accelerometer-measured sedentary and physical activity time and their correlates in European older adults: the SITLESS study. J Gerontol A Biol Sci Med Sci. 2020;75(9):1754-62.

6. Cocate PG, de Oliveira A, Hermsdorff HH, Alfenas RC, Amorim PR, Longo GZ, et al. Benefits and relationship of steps walked per day to the cardiometabolic risk factor in Brazilian middle-aged men. J Sci Med Sport. 2014;17 (3):283-7.

7. Severinsen MCK, Pedersen BK. Muscle-organ crosstalk: the emerging roles of myokines. Endocr Rev. 2020;41 (4):594-609.
8. Dirks ML, Wall BT, van de Valk B, Holloway TM, Holloway GP, Chabowski A, et al. One week of bed rest leads to substantial muscle atrophy and induces whole-body insulin resistance in the absence of skeletal muscle lipid accumulation. Diabetes. 2016;65(10): 2862-75.

9. Saltin B, Blomqvist G, Mitchell JH, Johnson-Jr RL, Wildenthal K, Chapman CB. Response to exercise after bed rest and after training. Circulation. 1968;38:1-78.

10. Lindholm ME, Marabita F, Gomez-Cabrero D, Rundqvist $\mathrm{H}$, Ekström TJ, Tegnér J, et al. An integrative analysis reveals coordinated reprogramming of the epigenome and the transcriptome in human skeletal muscle after training. Epigenetics. 2014;9(12):1557-69.

11. Liu Y, Gayle AA, Wilder-Smith A, Rocklöv J. The reproductive number of COVID-19 is higher compared to SARS coronavirus. J Travel Med. 2020(2);27:1-4.

12. Tison GH, Avram R, Kuhar P, Abreau S, Marcus GM, Pletcher MJ, et al. Worldwide effect of COVID-19 on physical activity: a descriptive study. Ann Intern Med. 2020;173(9):767-70.

13. Seyed AS, Mehrtak M, Mohsseni PM, Mirzapour P, Barzegary A, Habibi P, et al. Genetic susceptibility of COVID-19: a systematic review of current evidence. Eur J Med Res. 2021;26(1):46.

14. Sallis R, Young DR, Tartof SY, Sallis JF, Sall J, Li Q, et al. Physical inactivity is associated with a higher risk for severe COVID-19 outcomes: a study in 48440 adult patients. Br J Sports Med. 2021;55:1099-105.

15. Malta DC, Szwarcwald CL, Barros MB, Gomes CS, Machado IE, Souza Júnior PR, et al. The COVID-19 Pandemic and changes in adult Brazilian lifestyles: a cross-sectional study, 2020. Epidemiol. Serv. Saúde. 2020;29(4): e2020407

\section{Corresponding author}

Odilon Abrahin. Universidade Federal do Pará, Rua Augusto Corrêa 1, 66075-110 Guamá, Belém, PA, Brazil. E-mail: odilonsalim@hotmail.com.

Manuscript received on July 12, 2021

Manuscript accepted on October 19, 2021

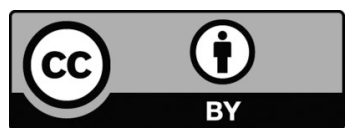

Motriz. The Journal of Physical Education. UNESP. Rio Claro, SP, Brazil - eISSN: 1980-6574 - under a license Creative Commons - Version 4.0 